\title{
IMPACT OF EDUCATIONAL TRAINING ON NEUROLOGICAL ASSESSMENT SKILLS OF FEMALE NURSES IN EVALUATING TRAUMATIC BRAIN INJURY PATIENTS THROUGH GLASGOW COMA SCALE IN LAHORE GENERAL HOSPITAL, LAHORE, PAKISTAN
}

\author{
Nazia Yousef, Kabir Ozigi Abdullahi, Kousar Perveen, Sadia Khan \\ Department of Nursing, Lahore School of Nursing, Faculty of Allied Health \& Sciences, The University of Lahore, \\ Lahore, Pakistan
}

\begin{abstract}
Background: Traumatic Brain Injury (TBI) is a leading cause of death and disability worldwide. The objective of this study was to determine the impact of educational training on neurological assessment skill of female nurses in evaluating traumatic brain injury patients through Glasgow Coma Scale in Lahore General Hospital, Lahore, Pakistan.

Material \& Methods: This quasi-experimental one group pre-posttest design study was conducted at Lahore School of Nursing, Faculty of Allied Health \& Sciences, The University of Lahore, Lahore, Pakistan from April 3, 2021 to May 15, 2021. Pre-test neurological assessment skill of 70 nurses was noted by an observer, two weeks educational training was given and four weeks later on, post-test score was noted. For neurological assessment skill, a 20 items observatory checklist was used. Age groups, marital status, job experience, work experience in recent department and work place were four demographic, while neurological assessment skill score was one research variable. Paired sample t test was used for hypothesis testing.

Results: Out 70 nurses, 26 (37.1\%) were in age group 25-30 years, $18(25.7 \%)$ in 31-35, $16(22.9 \%)$ in 36-40, six (8.6\%) in $41-45$ and four (5.7\%) in 46-50 years. Marital status was; $36(51.4 \%)$ single, $27(38.6 \%)$ married, three (4.3\%) divorced and four (5.7\%) widow. Job experience was; eight (11.4\%) had <2 years, $33(47.1 \%) 2-5$ years, $25(35.7 \%) 6-10$ years and four (5.7\%) had $>10$ years. Work experience in recent department was; $16(22.9 \%)$ had <1 year, $39(55.7 \%) 1-3$ years, $13(18.6 \%) 4-5$ years and two $(2.9 \%)$ had $>5$ years. Work place was Trauma Unit in $12(17.1 \%)$, neurosurgery ICUs in $38(54.3 \%)$ and surgical units in 20 (28.6\%) cases. Mean 16.89 \pm 2.52 posttest skills score was significantly higher than mean $12.56 \pm 2.67$ pretest skills score $(p=<.0001)$.

Conclusion: Our study confirmed that the effect of educational training was significant in improving neurological assessment skills of nurses in evaluating traumatic brain injury patients through Glasgow Coma Scale in Lahore General Hospital, Lahore, Pakistan. Further studies are suggested with increased sample size and multiple research settings.
\end{abstract}

KEY WORDS: Traumatic Brain Injury; Head Injuries: Brain Injuries; Neurological Assessment; Glasgow Coma Scale; Nursing Assessment, Skills; Nurses, Pakistan.

Cite as: Yousef N, Abdullahi KO, Perveen K, Khan S. Impact of educational training on neurological assessment skills of female nurses in evaluating traumatic brain injury patients through Glasgow Coma Scale in Lahore General Hospital, Lahore, Pakistan. Gomal J Med Sci 2021 Jul-Sep; 19(3):105-10. https://doi.org/10.46903/gjms/19.03.971

\section{Corresponding Author:}

Nazia Yousef

Post-graduate Scholar

Lahore School of Nursing

Faculty of Allied Health \& Sciences

The University of Lahore, Lahore, Pakistan

E-mail: naziayousif19@gmail.com

Date Submitted: 21-05-2021

Date Revised: 22-06-2021

Date Accepted: $\quad 26-06-2021$

\section{INTRODUCTION}

1.1 Background: Traumatic Brain Injury (TBI) is defined as contuse to the cerebrum. The National Center for Injury Prevention and Control characterizes a TBI as "a blow or shock to the head that disturbs the typical capacity of mind". There are several ways of TBls but the commonest are engine vehicle collision, injury to head and assault. Assessment of traumatic brain injury in emergency department should be multidimensional. This will help in making early and 
accurate diagnoses. It also helps in making decision about CT imaging. ${ }^{1}$

This aids in reduction of cost in needless testing and reduce the hospital stay. Sequential assessment gears in emergency can help in making appropriate clinical diagnosis. It provides objectivity and quantify. TBI is a leading cause of death and disability worldwide. Yearly, about 1.5 million people die from $\mathrm{TBI}$ and those several millions that survive receive emergency treatment. Neurological injuries affect 1.4 million people per year in Pakistan. ${ }^{2}$

In Finland, 101 to 221 per 100,000 population is the incidence rate yearly for TBI. In Pakistan, according to road traffic injury surveillance study $(n>100,000)$, one third of patients had a TBI and $10 \%$ of them had moderate to severe brain injury. Regardless of recorded burden, no accurate data is present related to emergency treatment for TBI.

The usual reception of TBI patients to the emergency department (ED) is with altered level of consciousness that needs urgent and efficient assessment. The Glasgow Coma Scale (GCS) provides objective assessment of level of consciousness in all types of medical and surgical patients during neurological assessment. ${ }^{3,4}$

The GCS has 3 main domains of assessment of level of consciousness, namely; eye opening $(E)$, verbal response $(\mathrm{V})$, and motor response $(\mathrm{M})$. The highest score is 15 and lowest 3 .

Two important factors of neurological evaluation are level of consciousness and motor response upon painful stimuli. GCS scoring is very helpful in evaluating trend of neurological functioning over the period of time. Quick and appropriate assessment, diagnosis and early treatment can reduce chances of many complications of brain trauma. In the extent of critical care, regardless of advancement in technology, neurological assessment plays a crucial part in the diagnosis and management of TBI patients. ${ }^{5}$

Sound knowledge and efficient skill performance of nurses may be helpful to deal with complexities of neurological assessment of such patients.

Assessment is the basic component of nursing process that helps in finding diagnoses and ruling out problems. Right after proper physical examination nurse organizes, analysis, and synthesizes collected data in a manner to figure out the patient's health care needs. ${ }^{6}$

Efficient nursing assessment was found associated with early patients recovery in neurosurgery and general surgery departments. ${ }^{7}$ A study reported that nurses, working in neurosurgery department have poor knowledge and practices about GCS assessment of TBI patients.

About $40 \%$ of all patients who admit in hospitals with traumatic brain injuries, rather to recover, their conditions get more worsen due to improper assessment and poor management. ${ }^{8}$

It is concluded from the above cited literature that the neurological competency of nurse can influence the prognosis of neurological clients. It has been observed many times that nurses are deficit in knowledge, skills and clinical confidence regarding neurology. Earlier studies reported that in service training can be very helpful in this regard. In service short courses are need of the hour for nurses to enhance the knowledge and competency related to neurology. This not only boasts the early recovery of patient but also reduce the financial burden of government.

Thus, to improve the ongoing traditional practices, there is huge need of changing the learning intervention to enhance the knowledge and skill for ultimately best patients' outcome that is the utmost objective of nursing practices. To the best of investigator awareness, formerly no study was published from Lahore, Pakistan on impact of educational intervention in improving the practices of nurses regarding neurological assessment of TBI patients on GCS.

1.2 Research Objective (RO): To determine the impact of educational training on neurological assessment skill of female nurses in evaluating traumatic brain injury patients through Glasgow Coma Scale in Lahore General Hospital, Lahore, Pakistan.

1.3 Research $\left(\mathrm{H}_{0}\right)$ Hypothesis $(\mathrm{RH})$ : There is no statistically significant impact of educational training on neurological assessment skill of female nurses in evaluating traumatic brain injury patients through Glasgow Coma Scale in Lahore General Hospital, Lahore, Pakistan.

\section{MATERIAL \& METHODS}

2.1 Design, duration, setting \& ethical considerations: This quasi-experimental one group pre-posttest design study was conducted in the Lahore School of Nursing, Faculty of Allied Health \& Sciences, The University of Lahore, Lahore, Pakistan from April 3, 2021 to May 15, 2021. Study was conducted according to the guidelines of declaration of Helsinki. Ethical and research committee approval was taken vide Notification No. IRB-UOL-FAHS/830-III/2021 from The University of Lahore. Written informed consent was taken from study subjects.

2.2 Population, sample size, sampling technique \& sample selection: The population of our study comprised 1,387 registered nurses of Lahore General Hospital. The sample size was calculated by using the following WHO formula. Software used $80 \%$ power and $Z_{a / 2}=1.96$. After adding up $20 \%$ drop off rate, the sample size was selected as $70 .{ }^{9}$ Mean and slandered deviation values were used from previously published studies. 


$$
\begin{gathered}
n=\frac{\sigma_{d}^{2}\left(Z_{\beta}+Z_{\alpha / 2}\right)^{2}}{\text { difference }} \\
\sigma_{d}=2.56 \quad Z_{\beta}=1.28 \\
\mu_{d}=52.87 \quad Z_{\alpha / 2}=1.96^{9}
\end{gathered}
$$

All the diploma holder female nurses were eligible. There was no male nurse working in our hospital at this time. Degree holders and those having specialization in neurosciences were excluded as they have sufficient skill due to their higher studies. Age group $>50$ years was excluded as they this group has sufficient skill due to their longer experience. Convenience sampling was used by choosing only morning nursing staff and purposive sampling was used to choose nurses from Accident \& Emergency Unit and three neurosurgical ICUs and three surgical units as these units receive almost all patients with TBI.

2.3 Conduct of procedure, intervention \& data collection checklist: In pre-assessment, the clinical assessor assessed the participants for skill competences at their original working place by maintaining anonymity through an "Observatory Checklist for
Neurological Assessment Skill (NAS)" of nurses in evaluating traumatic brain injury patients through Glasgow Coma Scale. One week educational training was given by specialized nursing instructor. In included one hour activity daily. The first three days included 30 minutes power point lecture and 10 minutes videos regarding GCS. The next three days included demonstration and skill performance at simulated live adult standardized patient regarding neurological assessment of traumatic brain injury (TBI) patients through GCS.

Further four weeks were given for improving neurological assessment skills. Then participants were reassessed for the same skills in a way as for pre-assessment.

For measuring NAS score, a 20 items observational checklist was used. Correctly performed skill step was marked as "achieved" and was scored as " 1 " and wrong or missed one step was marked as "not achieved" and scored as "0". ${ }^{10,11}$ The correct/ achieved items were added to give a final score of 0-20. The Cronbach's alpha for this check list was 0.723 and intra-rater reliability of the tool was reported as $0.86 .^{12}$ (Table 1 )

Table 1: Observatory Checklist for Neurological Assessment Skill (NAS) of nurses in evaluating traumatic brain injury patients through Glasgow Coma Scale

\begin{tabular}{|l|l|l|}
\hline No. & Competency checklist Items & $\begin{array}{c}\text { Achieved } \\
\text { Yes(1)/No (0) }\end{array}$ \\
\hline 1 & Performed hand washing & \\
\hline 2 & Correctly verified patient identification & \\
\hline 3 & Obtained consent about the procedure from patient or attendant & \\
\hline 4 & Maintain patient privacy during the procedure & \\
\hline 5 & Observe if eye open spontaneously & \\
\hline 6 & If patient is not opening his eyes; call patient's name twice & \\
\hline 7 & Pressing the lateral part of the nail bed to apply peripheral pain stimulus & \\
\hline 8 & Ask about time, place and person to check patient's orientation & \\
\hline 9 & Check for confusion & \\
\hline 10 & Check for inappropriate words & \\
\hline 11 & Check for incomprehensible sounds & \\
\hline 12 & Check for none response & \\
\hline 13 & Check patient if he obeys commands by instructing; squeezing your hand, close/open eyes & \\
\hline 14 & Apply the central pain stimulus (trapezius squeeze); If a patient is not obeying command & \\
\hline 15 & Observe if patient reacts to pain; localizing, withdrawing, abnormal flexion and extension & \\
\hline 16 & $\begin{array}{l}\text { Have nurse pen light or a torch for patient assessment of pupillary reaction. Check pupil size } \\
\text { before the reaction to light and able to differentiate pupil reactions; brisk, sluggish or fixed }\end{array}$ & \\
\hline 17 & $\begin{array}{l}\text { Correctly perform assessment of limb movements and able to differentiate; normal power/ } \\
\text { mild weakness/ severe weakness/no movement/abnormal posture (extension/flexion) }\end{array}$ & \\
\hline 18 & Summarize, interpret and report abnormal results of the GCS & \\
\hline 19 & Performed score aggregation & \\
\hline 20 & Categorize the scores & \\
\hline
\end{tabular}


2.4 Data collection plan: Data was collected for four categorical demographic variables (attributes); age groups (25-30/ 31-35/ 36-40/ 40-50, 46-50 years), marital status (married/ unmarried, divorced/ widow), job experience $(<2 / 2-5 / 6-10 />10$ years) and work experience in recent department $(<1 / 1-3 / 4-5 />5$ years).

There was one research variable on ratio scale; Neurological Assessment Skill (NAS) score.

2.5 Data analysis plan: The four demographic variables were analyzed by count and percentage. NAS score was analyzed by mean, minimum, maximum, range and SD with $95 \% \mathrm{Cl}$ for mean. Hypothesis was verified by paired samples t test. Mean \& SD of the two observations, difference of means, $95 \% \mathrm{Cl}$ of difference of means, $t$ value, degree of freedom \& significance ( $p$-value) are given at alpha .05. IBM SPSS version v.20 (IBM Inc., Armonk, NY) was used for statistical analysis.

\section{RESULTS}

3.1 Sample description by demographic variables: Out of a sample of 70 nurses, $26(37.1 \%)$ were in age group 25-30 years, 18 (25.7\%) in 31-35 years, $16(22.9 \%)$ in $36-40$ years, six (8.6\%) in $41-45$ years and four $(5.7 \%)$ in $46-50$ years. Marital status was; 36 (51.4\%) single, 27 (38.6\%) married, three (4.3\%) divorced and four (5.7\%) widow.

Job experience of nurses was; eight (11.4\%) had <2 years, $33(47.1 \%) 2-5$ years, 25 (35.7\%) 6-10 years and four $(5.7 \%)$ had $>10$ years. Work experience in recent department was; $16(22.9 \%)$ had $<1$ year, $39(55.7 \%) 1-3$ years, 13 (18.6\%) 4-5 years and two $(2.9 \%)$ had $>5$ years. Work place was Accident \& Emergency Unit in 12 (17.1\%), neurosurgery ICUs in $38(54.3 \%)$ and surgical units in $20(28.6 \%)$ cases.

3.2 Sample statistics and population parameters: Table 3.2 shows statistics for the sample and esti- mated parameters for the population for the research variable NAS score.

3.3 Hypothesis Testing: Paired t test showed $p$-value $<.0001$, rejecting the $\mathrm{H}_{0}$ and thus confirming that the difference between the pretest and posttest skill score is statistically significant. Hence the educational intervention was effective in improving neurological assessment skill of nurses. (Table 3.3)

\section{DISCUSSION}

Neurological assessment in emergency and intensive care units is the basic skill for nurses. It is recommended that effectiveness of practices could be enhanced through evidence based practices. Hence the present study aimed to investigate the impact of educational training in improving the practices of registered nurses.

Our study revealed mean pretest skill score of $12.56 \pm 2.67$ and mean posttest score of $16.89 \pm 2.52$, with mean difference of -4.33 after educational intervention. This difference was statistically significant $(<.0001)$ with calculated $t$ value of -11.90 , proving that the intervention has significant impact on enhancing nurses skill score.

All the four following studies favor our finding.

Devi, et al. ${ }^{13}$ from Pokhara, Nepal reported in 2018 (on scale of $0-20$ score) mean pretest knowledge score of $10.58 \pm 3.57(n=35)$ and mean posttest knowledge score of $16.32 \pm 1.79(n=31)$, with mean difference of -5.74 after educational intervention. This difference was statistically significant with calculated $t$ value of $-8.913\left(t_{(30)}=2.042\right)$, proving that the intervention has significant impact on enhancing nurses knowledge score. Skill score was tested on scale of 0-12 score. The mean pretest skill score was $5.42 \pm 2.159$ and mean posttest skill score was $9.38 \pm 1.94$, with mean difference of -3.96 after educational intervention. This difference was statistically

Table 3.2: Pre and post educational training scores of Neurological Assessment Skill of nurses in evaluating traumatic brain injury patients through Glasgow Coma Scale in Lahore General Hospital, Lahore, Pakistan $(n=70)$

\begin{tabular}{|l|c|c|c|c|c|c|c|}
\hline \multirow{2}{*}{ Observation } & \multirow{2}{*}{ Mean } & \multirow{2}{*}{ Minimum } & \multirow{2}{*}{ Maximum } & \multirow{2}{*}{ Range } & \multirow{2}{*}{ S.D } & \multicolumn{2}{|c|}{$95 \% \mathrm{Cl}$ for mean } \\
\cline { 7 - 9 } & & & & & & Lower & Upper \\
\hline Pretest Skill Score & 12.56 & 6 & 18 & 12 & 2.67 & 11.92 & 13.19 \\
\hline Posttest Skill Score & 16.89 & 13 & 20 & 7 & 2.52 & 16.28 & 17.48 \\
\hline
\end{tabular}

Table 3.3: Comparison of pre and post educational training scores of Neurological Assessment Skill of nurses in evaluating traumatic brain injury patients through Glasgow Coma Scale in Lahore General Hospital, Lahore, Pakistan $(n=70)$

\begin{tabular}{|c|c|c|c|c|c|c|c|c|}
\hline \multirow{2}{*}{ Variable } & \multirow{2}{*}{ Mean } & \multirow{2}{*}{ S.D } & \multicolumn{4}{|c|}{ Paired differences } & \multirow{2}{*}{ t-value } & \multirow{2}{*}{$p$-value } \\
\hline & & & Mean & SD & 95\%Cl Lower & 95\%CI Upper & & \\
\hline Pretest skills score & 12.56 & 2.67 & \multirow{2}{*}{-4.33} & \multirow{2}{*}{3.04} & \multirow{2}{*}{-5.05} & \multirow{2}{*}{-3.60} & -11.90 & \multirow{2}{*}{$<.0001$} \\
\hline Posttest skills score & 16.89 & 2.52 & & & & & d.f. $=69$ & \\
\hline
\end{tabular}


significant with calculated $\mathrm{t}$ value of $-9.36\left(\mathrm{t}_{(30)}=\right.$ 2.042), proving that the intervention has significant impact on enhancing nurses skill score.

Kumar, et al. ${ }^{14}$ from Abhipur, Mohali, Punjab, India has reported in 2015 the effect of self-instruction module (SIM) on level of knowledge of 50 nurses regarding medical and surgical management of patients with head injuries. Pre-test knowledge score was $13.16 \pm 2.33$ and post-test score was $24.04 \pm 2.65$, with significant increase in score with SIM $(p=<.001)$.

Kamothi ${ }^{15}$ from Ahmedabad, India reported in 2016 the effect of Planned Teaching Programme (PTP) on knowledge and practice of 40 nurses on Glasgow Coma Scale (GCS) of head injuries patients in ICUs. Knowledge and practice were assessed on structured knowledge questionnaire and structured observational check list respectively. Pre-test knowledge score was 14.225 and post-test was 28.25, with significant difference after PTP. Pre-test practice score was 1.37 and post-test was 5.2 , with significant difference after PTP.

Teles, et al. ${ }^{16}$ from Belgaum, India reported in 2013 the effect of SIM on knowledge and practice of 55 nurses working in critical care units regarding GCS in neurological assessment of patients. There was significant increase in mean knowledge score from $12.84 \pm 4.24$ pre-test score to $25.78 \pm 2.39$ post-test score. The increase in skill score was also significant from $7.64 \pm 2.79$ pre-test score to $11.45 \pm 2.21$ posttest score.

Enriquez, et al. ${ }^{17}$ selected 90 nurses, collected data on a pre-survey questionnaire, followed by 90 minutes educational intervention on GCS and then had a post-survey questionnaire. They concluded that standardized educational program has significantly improved the knowledge of nurses regarding GCS.

Jones from Murray, Utah, United States $(n=31)$ have shown significant increase in overall post-survey scores $(88.6 \pm 13.3)$ vs. pre-survey scores $(77.2 \pm 16.7)(p=0.001)$. Here a 40 minutes neurological assessment power point educational module was presented in lecture format in five different sessions to 31 nurses at Intermountain Medical Center (IMC) in Murray, Utah. The pre and post assessment was done by 17 items questionnaire on Likert scale.

\section{CONCLUSION}

Our study confirmed that the effect of educational training was significant in improving neurological assessment skills of nurses in evaluating traumatic brain injury patients through Glasgow Coma Scale in General Hospital, Lahore, Pakistan. The findings of current study support the need for ongoing education of nurses for neurological assessments to increase skill and confidence in assessment of neurological injuries, which ultimately could increase the patient survival rate. Further studies are suggested with increased sample size and multiple research settings.

\section{REFERENCES}

1. Hien NT, Chae S-M. The accuracy of Glasgow coma scale knowledge and performance among Vietnamese nurses. Perspectives Nur Sci 2011 Jun;8(1):54-61.

2. Khan TA, Hussain S, Ikram A, Mahmood S, Riaz $\mathrm{H}$, Jamil A, et al. Prevalence and treatment of neurological and psychiatric disorders among tertiary hospitals in Pakistan; findings and implications. Hosp Pract 2020 Aug;48(3):145-60. https://doi.or $\mathrm{g} / 10.1080 / 21548331.2020 .1762366$

3. Teasdale G, Jennett B. Assessment of coma and impaired consciousness: a practical scale. The Lancet 1974;304(7872):81-4. https://doi. org/10.1016/S0140-6736(74)91639-0

4. Teasdale G, Allen D, Brennan P, McElhinney E, Mackinnon L. The Glasgow Coma Scale: an update after 40 years. Nursing Times 2014; 110: 12-16.

5. Maher AB. Neurological assessment. Int J Orthop Trauma Nurs 2016 Aug;22:44-53. https://doi. org/10.1016/j.ijotn.2016.01.002

6. Greenshields S. Neurological assessment in children and young people. Br J Nurs 2019 Sep 13;28(16):1056-9. https://doi.org/10.12968/ bjon.2019.28.16.1056

7. Bae KS, Roh YS. Training needs analysis of Korean nurses' neurological assessment competency. Nurs Health Sci 2020;22(1):99-107. https://doi.org/10.1111/nhs.12654

8. Arsh A, Darain H, Haq ZU, Zeb A, Ali I, llyas SM. Epidemiology of spinal cord injuries due to bomb blast attacks, managed at paraplegic centre Peshawar, Pakistan: a nine years retrospective study. Khyber Med Uni J 2017 Apr-Jun;9(2):55-9.

9. Vink P, Tulek Z, Gillis K, Jönsson AC, Buhagiar J, Waterhouse $\mathrm{C}$, et al. Consciousness assessment: a questionnaire of current neuroscience nursing practice in Europe. J Clin Nurs 2018;27(2122):3913-9. https://doi.org/10.1111/jocn. 14614

10. Cook NF. The Glasgow Coma Scale: a European and global perspective on enhancing practice. Crit Care Nurs Clin North Am 2021;33(1):89-99. https://doi.org/10.1016/j.cnc.2020.10.005

11. Catangui E. Improving Glasgow Come Scale (GCS) competency of nurses in one acute stroke unit- a Nursing Initiative Project. J Nurs Pract 2019;3(1):109-15. https://doi. org $/ 10.36959 / 545 / 370$

12. Kotfis K, Zegan-Barańska M, Strzelbicka M, Safranow K, Żukowski M, Ely EW, et al. Validation of the Polish version of the Critical Care Pain Observation Tool (CPOT) to assess pain intensity in adult, intubated intensive care unit patients: the POL-CPOT study. Arch Med Sci 2018 Jun;14(4):880-89. https://doi.org/10.5114/ aoms.2017.69752 
13. Devi WA, Rana M. effectiveness of a planned teaching programme on glasgow coma scale among nurses working in critical care units of selected hospital, Pokhara, Nepal Int J Nurs Edu 2018;10(2):89-94. https://doi.org/10.5958/09749357.2018.00048.X

14. Kumar S. Effectiveness of self-instructional module (SIM) on knowledge regarding care of head injury patients among staff nurses working in selected hospitals, Punjab. Int J Pharm Sci Rev Res 2015;35(2):191-4.

15. Kamothi A. A study to assess the effectiveness of a planned teaching programme on Glasgow Coma Scale of head injury patient in terms of knowledge and practice among staff nurses working in intensive care units of selected government college attached hospitals of Gujarat state. Int J Novel Res Healthcare Nurs 2016;3(2):210-11
16. Teles M, Bhupali P, Madhale M. Effectiveness of self-instructional module on knowledge and skills regarding use of Glasgow Coma Scale in neurological assessment of patients among nurses working in intensive care units of KLE Dr. Prabhakar Kore Hospital and Medical Research Cetre, Belgaum. J Krishna Inst Med Sci Univ 2013;2(1):98-104.

17. Enriquez CM, Chisholm KH, Madden LK, Larsen AD, De Longpré T, Stannard D. Glasgow Coma Scale: generating clinical standards. J Neurosci Nurs 2019;51(3):142-6. https://doi.org/10.1097/ JNN.0000000000000448

18. Jones C. Neurological nursing assessment education at Intermountain Medical Center: a quality improvement project [dissertation on the internet]. Tucson. Arizona: The University of Arizona; 2018 [cited 2020 June 23]. Available at: https:// repository.arizona.edu/handle/10150/630194

\section{CONFLICT OF INTEREST}

Authors declare no conflict of interest. GRANT SUPPORT AND FINANCIAL DISCLOSURE None declared.

\section{AUTHORS' CONTRIBUTION}

The following authors have made substantial contributions to the manuscript as under:

Conception or Design:

Acquisition, Analysis or Interpretation of Data:

Manuscript Writing \& Approval:

$$
\begin{aligned}
& \text { NY, KOA } \\
& \text { NY, KOA, KP, SK } \\
& \text { NY, KOA, KP, SK }
\end{aligned}
$$

All the authors agree to be accountable for all aspects of the work in ensuring that questions related to the accuracy or integrity of any part of the work are appropriately investigated and resolved. 